SIGNS \& SYMPTOMS nephrotic syndrome - Diffuse maculopapular rash - Pruritis

\title{
THE CASE
}

A 24-year-old man with no past medical history was referred to a nephrologist for a 5-month history of leg swelling and weight gain. His only medication was furosemide $40 \mathrm{mg} / \mathrm{d}$, prescribed by his primary care physician. His physical examination was unremarkable except for lower extremity and scrotal edema.

Laboratory values included a creatinine of $0.8 \mathrm{mg} / \mathrm{dL}$ (reference range, 0.6 to $1.2 \mathrm{mg} / \mathrm{dL}$ ); hemoglobin concentration, $14.4 \mathrm{~g} / \mathrm{dL}$ (reference range, 14 to $18 \mathrm{~g} / \mathrm{dL}$ ); albumin, $1.9 \mathrm{~g} / \mathrm{dL}$ (reference range, 3.5 to $5.5 \mathrm{~g} / \mathrm{dL}$ ); and glucose, $80 \mathrm{mg} / \mathrm{dL}$ (reference range, 74 to $106 \mathrm{mg} / \mathrm{dL}$ ). Electrolyte levels were normal. Urinalysis revealed 3+ blood and 4+ protein on dipstick, as well as the presence of granular and lipid casts on microscopic exam. A 24-hour urine collection contained $10.5 \mathrm{~g}$ of protein. Antinuclear antibody titers, complement levels, hepatitis serologies, and antineutrophil cytoplasmic antibody titers were all normal.

A renal biopsy revealed idiopathic focal segmental glomerulosclerosis. The patient was started on oral prednisone $40 \mathrm{mg}$ twice daily.

Two days later, he developed a diffuse pruritic maculopapular rash. He stopped taking the prednisone, and the rash resolved over the next 3 to 5 days. He was then instructed to restart the prednisone for his nephrotic syndrome. When he developed a new but similar rash, the prednisone was discontinued. The rash again resolved.

\section{THE DIAGNOSIS}

Since the patient had already been taking furosemide for 6 weeks without an adverse reaction, it was presumed that the prednisone tablet was causing his rash. It would be unusual for prednisone itself to cause a drug eruption, so an additive or coloring agent in the tablet was thought to be responsible for the reaction.

We noted that the patient had been taking a 20-mg orange tablet of prednisone. So we opted to "tweak" the prescription and prescribe the same daily dose but in the form of 10 -mg white tablets. The patient tolerated this new regimen without any adverse effects and completed a full 9 months of prednisone therapy without any recurrence of skin lesions. His glomerular disease went into remission.

\section{DISCUSSION}

Excipients are inert substances that are added to a food or drug to provide the desired consistency, appearance, or form. They are also used as a preservative for substance stabilization.

There are many reports in the literature of adverse reactions to excipients. ${ }^{1-3}$ These include skin rashes induced by the coloring agent in the capsule shell of rifampicin ${ }^{2}$ and a rash

Neil E. Soifer, MD; Michael J. Hepner, MD Section of Nephrology, Louis A. Weiss Memorial Hospital, Chicago, IL (Dr. Soifer); Section of Allergy \& Immunology, Beaumont Health, Royal Oak, MI (Dr. Hepner)

- nsoifer@aol.com

The authors reported no potential conflict of interest relevant to this article. 


\section{$>$}

We prescribed the same daily dose but in the form of 10-mg white tablets. The patient tolerated this new regimen without any adverse effects. that developed from a coloring agent in oral iron. ${ }^{3}$ Other reports have noted dyes in foods and even toothpaste as triggers. ${ }^{4,5}$

I Hypersensitivity. Although a specific reaction to prednisone was considered unlikely in this case, type IV delayed hypersensitivity reactions to corticosteroids have been reported. The most common type of corticosteroid-related allergy is contact dermatitis associated with topical corticosteroid use. ${ }^{6}$ Many cases of delayed maculopapular reactions are thought to be T-cell-mediated type IV reactions. ${ }^{6}$

Type I immediate hypersensitivity reactions to corticosteroids are also well documented. In a literature review of $120 \mathrm{im}$ mediate hypersensitivity reactions to corticosteroids, anaphylactic symptoms were more commonly reported than urticaria or angioedema. ${ }^{7}$ Intravenous exposure was most frequently associated with reactions, followed by the intra-articular and oral routes of administration. $^{7}$

I Causative agents. The same literature review identified methylprednisolone as the most common steroid to cause a reaction; dexamethasone and prednisone were the least frequently associated with reactions. ${ }^{7}$ Pharmacologically inactive ingredients were implicated in $28 \%$ of the corticosteroid hypersensitivity reactions. $^{7}$

Additives suspected to be triggers include succinate and phosphate esters, carboxymethylcellulose, polyethylene glycol, and lactose. Interestingly, there have been reports of acute allergic reactions to methylprednisolone sodium succinate $40 \mathrm{mg} / \mathrm{mL}$ intravenous preparation in children with milk allergy, due to lactose contaminated with milk protein. ${ }^{8,9}$

I Yellow dye was to blame. In our case, the 20-mg tablet that the patient had been taking contained the coloring agent FD\&C yellow \#6, an azo dye also known as sunset yellow or E-110 in Europe. Several reports have described adverse reactions to this coloring agent. ${ }^{1,3}$ There were other additives in the 20-mg tablet, but a comparison revealed that the 10-mg tablet contained identical substances-but no dye. Thus, it was most likely that the coloring agent was the cause of the patient's probable type IV exanthematous drug reaction.

\section{Our patient}

The patient was instructed to avoid all medications and food containing FD\&C yellow \#6. No formal allergy testing or re-challenge was performed, since the patient did well under the care of his nephrologist.

\section{THE TAKEAWAY}

It's important to recognize that adverse drug reactions can occur from any medicationnot only from the drug itself, but also from excipients contained within. This case reminds us that when a patient complains of an adverse effect to a medication, dyes and inactive ingredients need to be considered as possible inciting agents.

JFP

\section{CORRESPONDENCE}

Neil E. Soifer, MD, Lakeside Nephrology, 2277 West Howard, Chicago, IL 60645; nsoifer@aol.com

\section{REFERENCES}

1. Swerlick RA, Campbell CF. Medication dyes as a source of drug allergy. J Drugs Dermatol. 2013;12:99-102.

2. Calişkaner Z, Oztürk S, Karaayvaz M. Not all adverse drug reactions originate from active component: coloring agent-induced skin eruption in a patient treated with rifampicin. Allergy. 2003;58:1077-1079.

3. Rogkakou A, Guerra L, Scordamaglia A, et al. Severe skin reaction to excipients of an oral iron treatment. Allergy. 2007;62:334-335.

4. Zaknun D, Schroecksnadel S, Kurz K, et al. Potential role of antioxidant food supplements, preservatives and colorants in the pathogenesis of allergy and asthma. Int Arch Allergy Immunol. 2012;157:113-124.

5. Barbaud A. Place of excipients in systemic drug allergy. Immunol Allergy Clin N Am. 2014;34:671-679.

6. Joint Task Force on Practice Parameters; American Academy of Allergy, Asthma and Immunology; American College of Allergy, Asthma and Immunology; Joint Council of Allergy, Asthma and Immunology. Drug allergy: an updated practice parameter. Ann Allergy Asthma Immunol. 2010;105:259-273.

7. Patel A, Bahna S. Immediate hypersensitivity reactions to corticosteroids. Ann Allergy Asthma Immunol. 2015;115:178-182.

8. Eda A, Sugai K, Shioya H, et al. Acute allergic reaction due to milk proteins contaminating lactose added to corticosteroid for injection. Allergol Int. 2009;58:137-139.

9. Levy Y, Segal N, Nahum A, et al. Hypersensitivity to methylprednisolone sodium succinate in children with milk allergy. J Allergy Clin Immunol Pract. 2014;2:471-474. 